\title{
Perancangan Aplikasi Pembelajaran Bahasa Jawa Berbasis Android
}

\author{
Ayu Ernawati ${ }^{1}$, dan Aries Saifudin ${ }^{2}$ \\ ${ }^{1,2}$ Teknik Informatika, Universitas Pamulang, Tangerang Selatan, Indonesia \\ e-mail: $\left\{{ }^{1}\right.$ ayuernawati443, ${ }^{2}$ aries.saifudin $\} @$ gmail.com
}

\begin{abstract}
The number of Javanese speakers is decreasing because many young people are not regularly using Javanese but rather use Indonesian, foreign languages, and slang languages. The structure of the Javanese and Indonesian is relatively similar. The Javanese language has a multilevel vocabulary so that it becomes a lot. Many and rarely used vocabularies make it easy to forget. Nowadays there are many people who use Android-based mobile devices. In this study proposed to make a Java language learning application based on Android to facilitate learning the Javanese language. The Java language learning application can be used by users to learn the Java language easily because it can use anytime and anywhere.
\end{abstract}

Keywords: Javanese language, applications, android

\section{Introduction}

Bahasa daerah termasuk salah satu unsur yang memiliki peranan penting dalam kebudayaan, antara lain menjadi kebanggaan suatu daerah, identitas daerah, dan media penghubung untuk komunikasi di keluarga dan masyarakat (Nurhasanah, Wurianto, \& Arifin, 2014). Hal ini diperkuat dengan adanya Undang-Undang Dasar 1945 mengenai pendidikan dan kebudayan pasal 32 ayat 2 yang dinyatakan bahwa bahasa daerah termasuk dalam kekayaan budaya nasional yang dihormati dan dipelihara oleh negara.

Saat ini yang masih setia menggunakan bahasa daerah terbatas usia lanjut. Hal ini dapat menyebabkan kepunahan bahasa daerah, sehingga perlu diusahakan semua kalangan terbiasa menggunakan bahasa daerah. Berkurangnya penggunaan bahasa daerah disebabkan oleh beberapa hal. Pertama, banyak orang menganggap bahasa daerah sebagai bahasa kuno dan sebagai bahasa masa lampau. Kedua, adanya anggapan bahwa bahasa daerah merupakan bahasanya orang miskin dan orang yang tidak berpendidikan. Ketiga, bahasa daerah hanya digunakan di daerah dan tidak berguna di luar kampung. Keempat, adanya anggapan bahwa bahasa daerah dapat menghambat kemajuan (Darwis, 2011).

Berdasarkan Lembaga Ilmu Pengetahuan Indonesia (LIPI) bahwasannya pada tahun 2016 Indonesia memiliki 617 bahasa daerah yang telah diidentifikasi oleh Badan Bahasa Kementrian Pendidikan Nasional, ada 15 bahasa daerah yang sudah tidak lagi digunakan orang dalam percakapan sehingga statusnya dinyatakan punah. Selain itu, ada 139 bahasa daerah di Indonesia yang terancam punah. Sehingga perlu adanya perhatian khusus untuk mencegah terjadinya kepunahan bahasa-bahasa daerah, karena terjadinya kepunahan bahasa termasuk penyebab terjadinya kepunahan peradaban penggunanya.

Bahasa adalah alat untuk komunikasi yang dapat digunakan untuk mengekspresikan pikiran dan perasaan dalam bentuk lisan maupun tulisan. Ekspresi dapat muncul akibat adanya dorongan maupun desakan dari dalam diri masing-masing untuk menyampaikan/mengungkapkan maksud tertentu kepada orang lain, sehingga dapat diterima dan memberikan kepuasan pribadi. Ekspresi yang disampikan dalam bentuk bahasa termasuk bagian dari identitas dan karakter seseorang karena dapat menunjukkan sifat-sifat orang yang menggunakan sehingga dapat diketahui karakter yang tersemunyi (Permadi, 2014).

Bahasa Jawa telah menjadi bahasa pertama dan utama bagi masyarakat suku Jawa baik yang masih tinggal di pulau Jawa maupun yang di luar pulau Jawa. Penduduk dari pulau Jawa yang ikut program transmigrasi masih banyak yang berkomunikasi menggunakan bahasa Jawa dalam keseharian. Penutur bahasa Jawa memiliki jumlah sekitar 75,5 juta. Bahasa Jawa berada pada urutan ke-11 dari 6.703 bahasa di dunia dalam jumlah penutur terbanyak. Bahasa mengalami perkembangan dari Jawa Kuno Purba menjadi bahasa Jawa Kuno, dan menjadi bahasa Jawa yang sekarang. Bahasa Jawa yang umum digunakan saat ini disebut sebagai bahasa Jawa baru/modern dan dipakai sejak sekitar abad ke-16 sampai saat ini (Wedhawati, et al., 2006). 
Bangsa yang besar yaitu bangsa yang selalu mengingat budayanya. Budaya menjadi satu bukti peradaban suatu masyarakat. Masyarakat Jawa merupakan salah satu suku bangsa yang menjadi bagian dari beragam suku bangsa di Indonesia. Berbagai hasil budaya banyak dihasilkan dan diwariskan secara turun temurun, salah satunya adalah bahasa Jawa dan aksara Jawa. Kelestarian hasil budaya tersebut tergantung pada masyarakat sebagai pelaku budaya dalam melestarikannya. Aksara Jawa nglegena atau yang dikenal dengan istilah carakan berjumlah 20 huruf, aksara tersebut disusun dengan urutan HANACARAKA, DATASAWALA, PADHAJAYANYA, dan MAGABATHANGA (Pitarto, 2017).

Aplikasi mobile merupakan aplikasi software yang dibuat khusus agar dapat dijalankan pada tablet dan juga smartphone (Irwansyah \& Moniaga, 2014). Sekarang ini banyak media untuk belajar bahasa daerah khususnya bahasa Jawa, mulai dari bentuk buku maupun aplikasi online, baik yang berbasis mobile, desktop dan web. Dan semuanya memiliki kekurangan dan kelebihan masing-masing. Media pembelajaran yang berbentuk buku mempunyai kelebihan dalam jumlah kosakata yang banyak, namun kelemahannya dalam ukuran, baik itu dari bentuknya ataupun ketebalannya, sehingga menyulitkan bagi pembaca dalam membawanya. Media pembelajaran dalam bentuk aplikasi online memiliki kekurangan yaitu hanya dapat diakses pada saat tersambung ke internet, dan kelebihannya hemat tempat karena hanya disimpan dalam satu penyimpanan (storage), misalnya disimpan dalam harddisk, flashdisk atau smartphone.

\section{Penelitian Terkait}

Pada penelitian Setiawan, Buana, dan Sukarsa (Setiawan, Buana, \& Sukarsa, 2014) menjelaskan bahwa penggunaan telepon pintar (smartphone) sudah banyak digunakan di masyarakat sebagai salah satu media komunikasi sekarang ini. Berbagai macam aplikasi telah dikembangkan dan terinstal dalam perangkat telepon pintar (smartphone) untuk membantu aktivitas masyarakat dan meningkatkan kinerjanya. Aplikasi penerjemah juga banyak dibutuhkan dan digunakan untuk membantu dalam menerjemahkan berbagai bahasa baik bahasa asing maupun daerah. Penelitian ini memiliki tujuan untuk membuat rancangan dan membuat aplikasi penerjemah digital dari bahasa Jawa ke bahasa Indonesia dan sebaliknya untuk perangkat bergerak (mobile) berbasis Android. Dengan aplikasi ini pengguna dapat menerjemahkan bahasa Jawa ke dalam bahasa Indonesia atau sebaliknya di mana pun dan kapan pun. Aplikasi penerjemah ini dikembangkan dengan Java 2 Micro Edition. Pengembangan aplikasi penerjemah ini dikerjakan dengan beberapa tahapan. Tahapan pertama dilakukan dengan menganalisa permasalahan dan mengidentifikasi kebutuhan. Tahapan berikutnya dilakukan dengan membuat rancangan aplikasi yang mencakup proses, antarmuka, dan media penyimpanan yang digunakan untuk menyimpan basis data. Metode pencarian yang digunakan dalam aplikasi penerjemah ini adalah brute force dan binary search. Aplikasi penerjemah yang telah dikembangkan dapat menampilkan hasil terjemahan sehingga dapat dijadikan alat penerjemah dan membantu mempelajari bahasa daerah. Tetapi aplikasi penerjemah ini hanya dapat mengubah dari bahasa Indonesia menjadi bahasa Jawa ngoko.

Pada penelitian Sigit dan Anwar (Sigit \& Anwar, 2015) menjelaskan bahwa Indonesia merupakan negara yang mempunyai banyak keberagaman bahasa daerah yang merupakan kekayaan yang harus dilestarikan. Bahasa Jawa merupakan salah satu dari bahasa daerah di Indonesia yang harus dilestarikan. Salah satu upaya yang dilakukan yaitu membuat kamus digital bahasa Jawa pad perangkat mobile yaitu Smartphone dengan sistem operasi Android. Perangkat lunak kamus digital ini dikembangkan menggunakan Eclipse dan basis datanya menggunakan MySQL server. Desain aplikasi ini menggunakan metode algoritma Knuth Morris Pratt (KMP) untuk mencari string kata-kata bahasa Jawa yangakan dicari terjemahannya ke dalam bahasa Indonesia. Tujuan utama dari aplikasi pembelajaran bahasa Jawa-Indonesia ini yaitu membantu pengguna mengubah bahasa Jawa ke dalam bahasa Indonesia dengan mudah sehingga pengguna dapat mempelajari bahasa Jawa dengan cepat.

Pada penelitian Kurniawan, Simon dan Irwansyah (Kurniawan, Simon, \& Irwansyah, 2013) menjelaskan bahwa bahasa telah menjadi alat untuk berinteraksi yang sangat bermanfaat bagi masyarakat. Komunikasi akan lebih efektif apabila saling memahami satu sama lain tentang apa yang sedang dibicarakan. Jumlah penggunaan bahasa daerah untuk komunikasi sehari-hari terus mengalami penurunan. Penurunan ini banyak terlihat dari banyaknya generasi muda yang terbiasa menggunakan bahasa gaul dalam berkomunikasi dibandingkan dengan menggunakan bahasa daerah. Pelestarian bahasa daerah merupakan hal yang perlu dilakukan di 
tengah perkembangan dan penggunaan teknologi yang semakin meningkat. Kamus elektronik merupakan salah satu media yang dapat dijadikan solusi untuk memperkenalkan dan mempermudah belajar berbagai bahasa daerah yang terdapat di Indonesia. Aplikasi ini dibangun menggunakan program Eclipse dan SQLite sebagai basis datanya.

Penelitian ini hanya menggunakan lima bahasa daerah sebagai contoh. Bahasa yang dipilih dan diambil contoh kosakatanya adalah bahasa Jawa, Melayu, Sunda, Minang dan Batak. Bahasa yang bukan daerah dipilih bahasa Indonesia dan bahasa Inggris. Sehingga kelebihan dari aplikasi ini pengguna dapat menerjemahkan bahasa daerah ke dalam bahasa-bahasa yang diambil sampelnya, dan juga aplikasi ini dapat digunakan tanpa harus terhubung dengan sambungan internet. Setelah memilih bahasa yang akan diubah, kemudian sistem akan mencari terjemahan dari kosakata yang dimasukkan oleh pengguna. Kosakata terjemahan yang ditampilkan diambil dari basis data yang telah tersimpan. Aplikasi yang dikembangkan akan menampilkan kosa kata yang ditemukan sebagai hasil terjemahan.

Implementasi antarmuka aplikasi ini terbagi menjadi dua buah form, yaitu form terjemahan dan form bantuan. Pada halaman terjemah terdapat beberapa masukan berupa tombol (button) dan textbox kosakata. Tombol (button) yang disediakan terdiri dari tombol untuk memilih bahasa asal, tombol untuk memilih bahasa tujuan, tombol untuk mengubah bahasa, tombol untuk menerjemahkan, tombol simpan, tombol keluar dan tombol bantuan. Sedangkan Textbox yang disedikan terdiri dari textbox untuk kata asal dan textbox untuk kata terjemahan. Fungsi tombol bantuan digunakan untuk menampilkan hal-hal yang berhubungan dengan cara menggunakan aplikasi. Hanya saja kekurangannya ada pada kosakata, karena kosakata yang terdapat dalam aplikasi ini hanya sebanyak 50 kata untuk setiap bahasa yang terdaftar, sehingga total kosa kata hanya ada 350 kata dalam basis data.

\section{Metodologi}

\section{Sistem Saat Ini}

Pada saat ini pembelajaran bahasa dan aksara Jawa masih sangat jarang didapatkan di Indonesia, dikarenakan pola bahasa dan ejaan yang sangat rumit untuk dimengerti menjadi faktor yang mempengaruhi pembelajaran bahasa dan aksara Jawa. Ditambah dengan masuknya budaya asing yang lebih menarik, menjadikan bahasa Jawa tidak terlalu diminati, jangankan dengan bahasa Jawa bahkan kesenian Jawa seperti musik-musik tradisional seperti gamelan, pertunjukan pewayangan yang menjadi identitas orang Jawa sudah tidak begitu diminati lagi, terutama pada kalangan muda atau remaja. Mereka lebih tertarik dengan budaya asing misalnya dengan budaya pakaian orang barat yang dikatakan fashionable atau malah budaya musik modern dari Korea yang biasa disebut K-pop. Pada saat ini pembelajaran bahasa dan aksara jawa hanya dilakukan di SD (Sekolah Dasar) dan hanya sampai pada SLTP (Sekolah Lanjutan Tingkat Pertama). Sedangkan pada tingkat SLTA (Sekolah Lanjutan Tingkat Atas) baik SMU (Sekolah Menengah Umum) maupun SMK (Sekolah Menengah Kejuruan) sudah mulai jarang yang diajarkan. Kurangnya minat baca buku juga menjadi kendala lain yang membuat proses pembelajaran kurang optimal, sehingga perlu adanya suatu aplikasi sebagai sarana untuk belajar bahasa daerah mudah digunakan dan dapat digunakan kapan pun dan di mana pun.

\section{Sistem Usulan}

Pada perancangan aplikasi pembelajaran bahasa Jawa ini ditetapkan beberapa batasan agar masalah dapat terselesaikan dan tujuan dapat tercapai. Pada panelitian ini akan dianalisa terlebih dulu untuk mencari alternatif penyelesaian masalah berdasarkan persyaratan-persyaratan perangkat lunak yang harus ada. Berdasarkan hasil analisa, selanjutnya akan dibuat rancangan aplikasi sesuai kebutuhan yang telah ditetapkan. Aplikasi akan dibuat menggunakan bahasa pemrograman JavaScript, HTML5, CSS, Ionic Framework, dan $M y S Q L$ sebagai aplikasi pendukung untuk menyimpan basis data. Agar dapat digunakan secara offline, basis data diunduh dan dikonversi dari webapp menjadi sqlite, kemudian dijadikan satu dalam paket instalasi aplikasi android.

Secara umum rancang sistem dibuat untuk memberikan gambaran tentang perangkat lunak yang baru atau sistem usulan. Rancangan ini mengidentifikasi secara rinci komponen apa saja yang ada pada aplikasi yang dirancang.

Aplikasi adalah perangkat lunak (software) yang diciptakan guna membantu segala aktifitas yang biasa dikerjakan oleh manusia (Pramana, 2005). Dengan demikian aplikasi adalah program komputer yang dibuat dengan tujuan untuk membantu manusia agar lebih efektif dan efisien. 


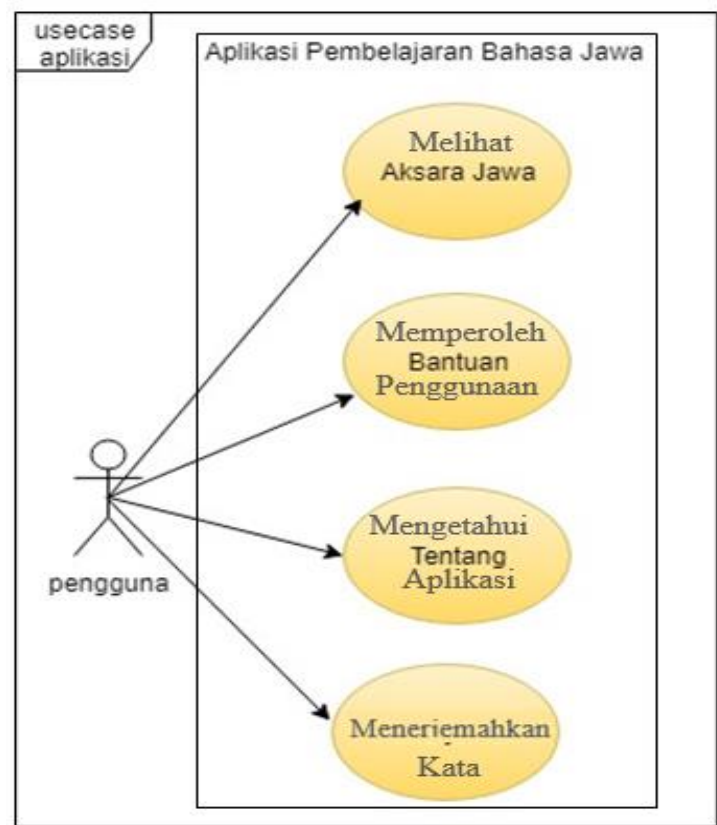

Gambar 1 Use Case Diagram Aplikasi Pembelajaran Bahasa Jawa

Use case diagram adalah gambaran hubungan antara aktor dan sistem. Diagram ini memberikan gambaran keseluruhan sistem dan aktor, maka komponen yang dipakai pun sangat sedikit (Mulyani, 2016). Use case diagram dibuat untuk memberikan gambaran bagaimana pengguna berinteraksi dengan sistem, dan fungsi apa saja di dalam sistem yang dapat digunakan oleh pengguna. Pada Gambar 1 merupakan gambaran use case diagram aplikasi pembelajaran bahasa Jawa.

\section{Hasil Eksperimen}

Tahap implementasi dilakukan setelah perancangan sistem selesai. Implementasi rancangan sistem dilakukan untuk menerjemahkan rancangan menjadi kode program yang dapat dieksekusi. Hasil dari tahap implementasi adalah program komputer yang menggunakan bahasa pemrograman tertentu yang dimengerti oleh mesin.

Pengembangan sistem pada penelitian ini diusulkan menggunakan IONIC Framework. Pengetikan kode program menggunakan aplikasi Sublime Text versi 3.0, dan MySQL sebagai basis datanya.

Spesifikasi perangkat keras (hardware) yang digunakan adalah untuk mengimplementasikan perangkat lunak kamus bahasa Jawa berbasis android berupa laptop. Sedangkan perangkat keras yang digunakan untuk menjalankan aplikasi pembelajaran bahasa Jawa berupa smartphone. Spesifikasi keduanya dapat dilihat pada Tabel 1 dan Tabel 2.
Tabel 1 Spesifikasi laptop

\begin{tabular}{|c|c|}
\hline Perangkat Keras & Keterangan \\
\hline Processor & AMD A8-7410 Quad-Core APU \\
\hline Memory & 4 GB \\
\hline Harddisk & 500GB \\
\hline Display & 14" HD (1366x768) \\
\hline
\end{tabular}

Tabel 2 Spesifikasi smartphone

\begin{tabular}{|c|c|}
\hline Perangkat Keras & Keterangan \\
\hline Processor & $2.3 \mathrm{GHz}$ \\
\hline Memory & $3 \mathrm{~GB}$ \\
\hline Harddisk & $36 \mathrm{~GB}$ \\
\hline Display & $5.5 \mathrm{inch}$ \\
\hline
\end{tabular}

Tabel 3 Spesifikasi software pendukung

\begin{tabular}{|c|c|}
\hline Perangkat Keras & Keterangan \\
\hline Sistem operasi & Windows 10 64-bit \\
\hline Aplikasi & Ionic framework, sublime text \\
\hline Sistem operasi & Android V6.0.1 (Marshmallow) \\
\hline Browser & Mozilla firefox, google chrome \\
\hline Database & MySQL v.3.2.2 \\
\hline
\end{tabular}

Setelah mengimplementasikan desain basis data dan aplikasi yang telah dibuat, aplikasi yang dibuat memiliki tampilan yang ditunjukkan pada Gambar 2 dan Gambar 3. Pada Gambar 2 menunjukkan tampilan penerjemah bahasa Jawa menjadi bahasa Indonesia. Sedangkan Gambar 3 menunjukkan tampilan untuk penerjemah bahasa Indonesia menjadi bahasa Jawa.

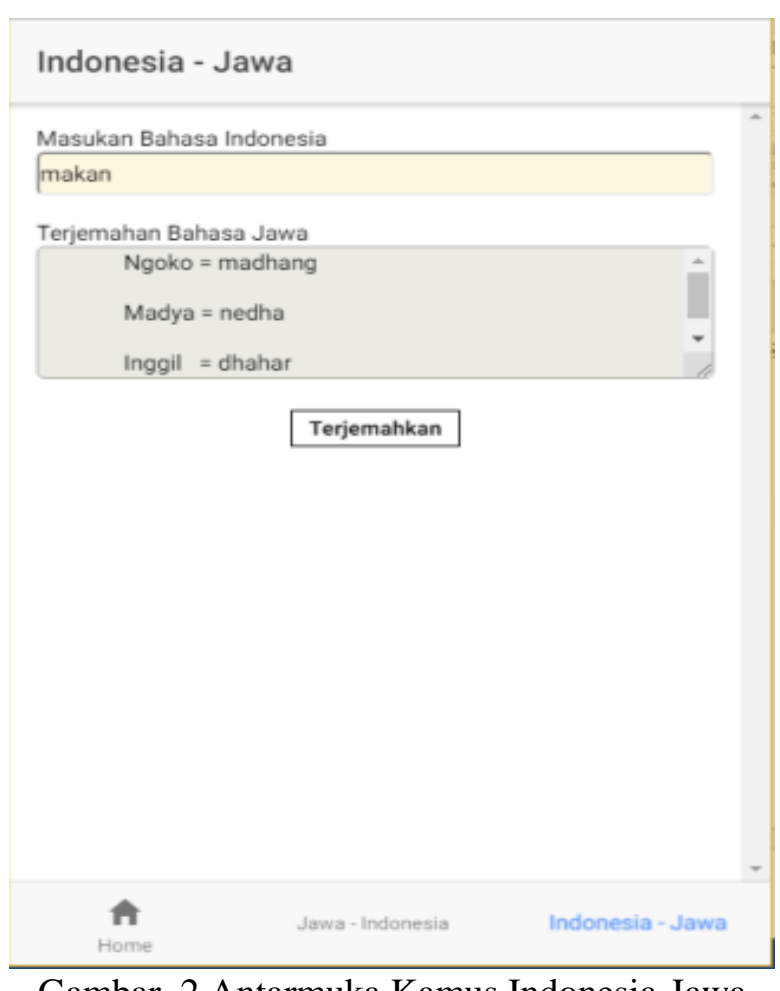

Gambar 2 Antarmuka Kamus Indonesia-Jawa 


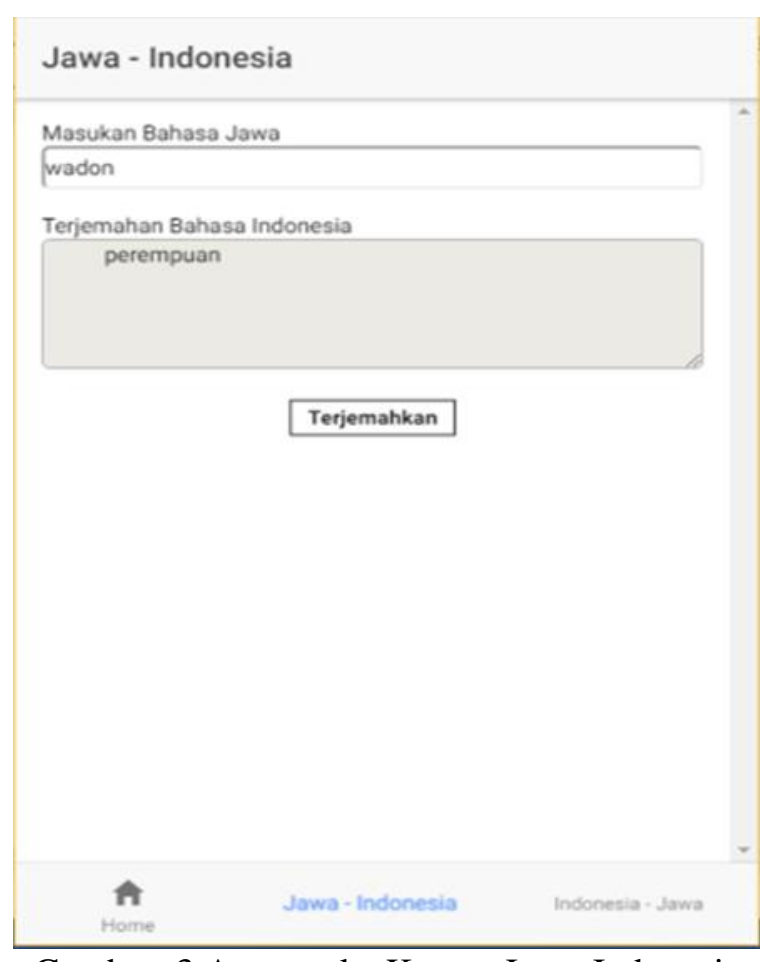

Gambar 3 Antarmuka Kamus Jawa-Indonesia

Pengujian merupakan satu elemen dari verifikasi dan validasi. Untuk memastikan software secara tepat dapat mengimplementasikan fungsi tertentu, dan untuk memastikan perangkat lunak dapat ditelusuri hingga ke persyaratan yang diminta pelanggan. Pengujian sofware merupakan elemen penting sebagai jaminan terhadap kualitas suatu software dan merepresentasikan spesifikasi, desain, dan pengkodean. Testabilitas sebuah software adalah pengujian sebuah program komputer dengan cara seberapa mudah program tersebut dapat digunakan. Karena itu perlu diketahui apa saja yang dapat dilakukan program tersebut menjadi mudah digunakan (Maturidi, 2014).

Guna mengetahui apakah aplikasi sudah memenuhi persyaratan yang ditetapkan, maka dilakukan verifikasi dan validasi menggunakan teknik pengujian black box. Teknik pengujian black box digunakan untuk menguji perangkat lunak dengan difokuskan pada spesifikasi yang bersifat fungsional.

Pengujian aplikasi kamus bahasa Jawa menggunakan teknik pengujian black box bertujuan untuk memastikan bahwa semua fungsional yang telah ditetapkan sudah lengkap dan berfungsi dengan benar. Pada pengujian black box, keberhasilan software yang diuji difokuskan hanya pada hasil keluaran berdasarkan masukan yang diberikan serta kondisi perangkat lunak. Pengujian black box tidak mempertimbangkan bagaimana alur pemrosesan dari fungsi perangkat lunak.
Pengujian ini memungkinan untuk menganalisa sistem dengan memberikan sekumpulan masukan, memproses, sampai memberikan hasil sesuai fungsi perangkat lunak. Tujuan utama dari pengujian black box adalah untuk mencari berbagai kesalahan yang mungkin ada pada:

a. Fungsi perangkat lunak yang hilang atau belum dibuat, yaitu untuk melakukan validasi apakah semua fungsi sudah memberikan hasil yang benar, dan melakukan verifikasi apakah semua fungsi yang dibutuhkan sudah ada.

b. Antarmuka (interface) yang tidak tepat.

c. Struktur data atau cara akses ke basis data yang tidak tepat.

d. Informasi yang dihasilkan mungkin mengandung kesalahan.

e. Kesalahan pada saat inisialiasi atau tujuan pengembangan perangkat lunak.

Untuk menguji aplikasi pembelajaran bahasa Jawa yang telah dikembangkan digunakan teknik pengujian black box. Sebagian hasil pengujian yang telah dilakukan ditunjukkan pada Tabel 4.

Hasil pengujian menggunakan teknik black box pada aplikasi pembelajaran bahasa Jawa menunjukkan tidak adanya kesalahan/cacat. Sehingga secara fungsional aplikasi pembelajaran ini telah memenuhi persyaratan yang ditetapkan.

Tabel 4 Pengujian Black Box Halaman Penerjemah

\begin{tabular}{|c|c|c|c|c|}
\hline No & $\begin{array}{c}\text { Skenario } \\
\text { Pengujian }\end{array}$ & $\begin{array}{c}\text { Hasil yang } \\
\text { Diharapkan }\end{array}$ & $\begin{array}{c}\text { Hasil } \\
\text { Pengujian }\end{array}$ & Status \\
\hline 1 & $\begin{array}{l}\text { Mengosongkan } \\
\text { masukan kata } \\
\text { kemudian } \\
\text { mengklik } \\
\text { tombol } \\
\text { terjemahkan }\end{array}$ & $\begin{array}{l}\text { Sistem akan } \\
\text { menampilkan } \\
\text { keterangan } \\
\text { "Tidak } \\
\text { ditemukan" }\end{array}$ & $\begin{array}{l}\text { Sistem dapat } \\
\text { menampilkan } \\
\text { keterangan } \\
\text { "Tidak } \\
\text { ditemukan" }\end{array}$ & Berhasil \\
\hline 2 & $\begin{array}{l}\text { Mengisi kata } \\
\text { yang tidak } \\
\text { sesuai } \\
\text { kemudian } \\
\text { menekan } \\
\text { tombol } \\
\text { terjemahkan }\end{array}$ & $\begin{array}{l}\text { Sistem tidak } \\
\text { menerjemahka } \\
\text { n dan } \\
\text { memberikan } \\
\text { keterangan } \\
\text { "Tidak } \\
\text { ditemukan" }\end{array}$ & $\begin{array}{l}\text { Sistem tidak } \\
\text { menerjemahk } \\
\text { an dan } \\
\text { memberikan } \\
\text { keterangan } \\
\text { "Tidak } \\
\text { ditemukan" }\end{array}$ & Berhasil \\
\hline 3 & $\begin{array}{l}\text { Mengisi kata } \\
\text { dengan benar } \\
\text { kemudian } \\
\text { menekan } \\
\text { tombol } \\
\text { terjemahkan }\end{array}$ & $\begin{array}{l}\text { Sistem } \\
\text { memberikan } \\
\text { hasil } \\
\text { terjemahan } \\
\text { dari kata yang } \\
\text { diterjemahkan }\end{array}$ & \begin{tabular}{|l|} 
Sistem \\
memberikan \\
hasil \\
terjemahan \\
dari kata yang \\
diterjemahkan \\
\end{tabular} & Berhasil \\
\hline
\end{tabular}




\section{Kesimpulan}

Dengan aplikasi pembelajaran ini pengguna dapat dengan mudah mempelajari bahasa Jawa di sewaktu-waktu ketika memiliki waktu luang, dan di mana pun, serta tidak harus terhubung dengan internet. Aplikasi pembelajaran ini dapat diinstalasi di perangkat mobile berbasis Android yang sudah banyak orang yang memiliki, sehingga mudah dibawa dan digunakan dibandingkan dengan menggunakan media buku.

\section{Daftar Pustaka}

Darwis, M. (2011). Nasib Bahasa Daerah di Era Globalisasi: Peluang dan Tantangan. Workshop Pelestarian Bahasa Daerah Bugis Makassar (pp. 1-13). Makassar: Balitbang Agama Makassar.

Kurniawan, D. E., Simon, R., \& Irwansyah. (2013). Aplikasi Kamus Aneka Bahasa Daerah Berbasis Smartphone Android. Seminar Nasional Teknologi Informasi, Komunikasi, dan Industri, (pp. 1-5). Pekanbaru.

Maturidi, A. D. (2014). Metode Penelitian Teknik Informatika. Yogyakarta: Deepublish.
Mulyani, S. (2016). Metode Analisis dan Perancangan Sistem. Bandung: Abdi Sistematika.

Nurhasanah, Wurianto, A. b., \& Arifin, B. (2014). Pengembangan Media KIJANK (Komik Indonesia, Jawa, dan Aksara Jawa) Pembelajaran Bahasa Jawa. Jurnal Pemikiran dan Pengembangan SD, 267-273.

Permadi, Y. (2014). Peran Bahasa, Sastra, dan Pembelajarannya. Prosiding Seminar Nasional (pp. 434-444). Bandung: Program Studi Pendidikan Bahasa dan Sastra Indonesia.

Pitarto, E. (2017). Mengenal Aksara Jawa Dengan Metode AMBAR. Yogyakarta: B-Books.

Pramana, H. W. (2005). Aplikasi Penjualan Berbasis Access 2003. Jakarta: PT. Elex Media Komputindo.

Setiawan, A. B., Buana, P. W., \& Sukarsa, I. M. (2014). Aplikasi Translator Bahasa Jawaa ke Bahasa Indonesia Berbasis Android. Merpati, 344-350.

Sigit, T. H., \& Anwar, K. (2015). Aplikasi Android Kamus Bahasa Jawa-Indonesia Menggunakan Algoritma Knutt Morris Pratt. PROTEKINFO, 29-33.

Wedhawati, Nurlina, W. E., Setiyanto, E., Marsono, Sukesti, R., \& Baryadi, P. (2006). Tata Bahasa Jawa Mutakhir. Yogyakarta: Kanisius. 